Res Publica. Revista de Historia de las Ideas Políticas ISSN: $1576-4184$

http://dx.doi.org/10.5209/RPUB.59694

\title{
La razón de Estado. Política y ontología en Spinoza
}

\author{
José Sánchez Tortosa*
}

Recibido: 3 de octubre de 2016 / Aceptado: 11 de diciembre de 2017

Resumen. La teoría política de Spinoza y, dentro de ella, el análisis de la democracia como forma de Estado, ejerce una crítica materialista de los dogmas escolásticos e ilustrados basada en la redefinición de la racionalidad política, concebida como una secuencia de la racionalidad de la Substancia infinita, red causal múltiple ajena a voluntad y entendimiento. En ese marco analítico, la democracia es una teocracia ontológica, el gobierno de las leyes necesarias a la escala de lo político y con vistas a la estabilidad del Estado.

Palabras clave: Spinoza; política; ontología; física; democracia.

\section{[en] The Reason of State. Politics and Ontology on Spinoza}

\begin{abstract}
Spinoza's political theory and within it the analysis of democracy as a form of State, exercises a materialist criticism of scholastic and enlightened dogma, based on the redefinition of political rationality, conceived as a sequence of the reason of infinite Substance, multiple causal networks unaware of understanding and will. Inside this analytical frame, democracy is an ontological theocracy, government of necessary laws in political scale and overlooking the stability of State.
\end{abstract}

Keywords: Spinoza; politics; ontology, physics; democracy.

Sumario: 1. La inversión genealógica y la estabilidad del Estado. 2. La lógica de lo irracional o la política de las pasiones. 3. Obediencia al Estado por consenso. 4. Democracia teocrática. 5. Democracia ficción.

Cómo citar: Sánchez Tortosa, J. (2018). La razón de Estado. Política y ontología en Spinoza, en Res publica 21.1, 13-30.

\section{La inversión genealógica y la estabilidad del Estado}

La naturaleza perecedera de las sociedades, como la de todo individuo compuesto (un individuo simple es un concepto límite, una ficción teórica), impone la necesidad de una renovación cíclica que consista en un regreso a los principios ${ }^{1}$, condición de su permanencia o estabilidad política ${ }^{2}$. Esta revolución, si tomamos el concepto en su significado técnico original de retorno al punto de inicio, es una corrección orientada a evitar, en lo posible, la descomposición del cuerpo político (compuesto) por medio

\footnotetext{
* Universidad Complutense de Madrid

josesancheztortosa@gmail.com

"ritirare verso i suoi principii".

“non si rinnovando, questi corpi non durano" (N. Maquiavelo, Discursos sobre la primera década de Tito Livio, III, 1).
} 
de una recomposición interna de las relaciones entre sus partes a través de las propias instituciones del Estado. Sólo así sería viable recuperar la potencia política constituyente, ya perdida o en caída. Esta medida posibilita la defensa frente a la disolución interna y frente a las amenazas externas de otros cuerpos políticos. Spinoza comienza el último capítulo del Tratado político ${ }^{3}$ dedicado a la aristocracia (capítulo X) recordando este dictamen de Maquiavelo. El principio del regreso a los fundamentos puede vincularse con la inversión genealógica (no cronológica) establecida por Spinoza en el Tratado político, VIII, 12, según la cual la secuencia clásica implícita en el paso del Estado de Naturaleza al Estado de sociedad (monarquía-aristocracia-democracia) queda desautorizada y se presenta bajo el orden contrario: democracia-aristocraciamonarquía. De ese modo, tal regreso supondría el intento por restablecer la potencia de permanencia de esa democracia originaria, viable en núcleos políticos muy delimitados, entendiendo que la democracia es la forma de Estado más estable, la que más incrementa la potencia, la perseverancia en el ser, la que más eficazmente reduce los riesgos de desviación técnica con respecto al bien común. Esa renovación o transformación de los elementos estructurales del Estado se produce necesariamente. La alternativa que se abre es cuál sea la causa del cambio. Puede producirse por causa intrínseca, esto es, por la fuerza (virtud) de la ley o por el ejemplo y la virtud (fuerza) de un hombre ejemplar, o por causa extrínseca ("casu contingere"), es decir, contingen$\mathrm{te}^{4}$. Esto último no puede querer decir otra cosa que por causa ignorada, es decir, imprevista o inesperada políticamente. Dicho de otro modo, la permanencia en el tiempo está garantizada por el virtuosismo político que sólo la ley o algún individuo excepcional proporcionan, de modo que su derrumbamiento sólo vendrá dado por el decurso inexorable de los acontecimientos que acotan en el tiempo toda realidad finita. Por el contrario, en ausencia de esa virtud de las leyes o de los soberanos, la descomposición acaecerá debido a su propia debilidad interna. En este segundo caso, el Estado como unidad política tendrá una duración inestable y proporcionalmente breve por ser un individuo político (compuesto) defectuoso, infecto, sin la debida cohesión entre sus partes. El alcance que para la teoría política tiene esta aportación de Spinoza se nos antoja de incalculable valor por su aplicabilidad a la política actual. La disolución del Estado no es menos necesaria, por tanto, que la extinción de los organismos en el plano de la biología o la llegada al estado de reposo de los cuerpos en el plano de la física. Así mismo, la estabilidad de un Estado es necesaria, tanto como su disolución. En ambos casos concurren causas (necesarias). En el primer caso, las causas de la estabilidad residen en la propia fuerza o virtud del Estado ("sua virtute"), que dependen, a su vez, de la fuerza o virtud de los hombres ejemplares y de las instituciones. En el segundo, de su debilidad interna ("suo vitio") o por la confrontación con fuerzas externas más poderosas ("inevitabili fato"), según lo establecido en el axioma de la parte IV de la Ética ${ }^{5}$. Dada, por tanto, la situación crítica en la que un Estado está en peligro de disolución, caben medidas políticas de urgencia, como el recurso temporal al supremus dictator. Esas medidas obedecen al criterio maquiaveliano de retorno a

3 B. Spinoza, Tratado político, Madrid, Alianza Editorial, 1986, trad.: A. Domínguez. A partir de ahora TP. Las citas de Spinoza según la Edición Gebhardt aparecen con la letra G. En este caso, G III.

4 No casualidad, que es como traduce A. Domínguez y que es inadmisible, ni siquiera metafóricamente, en la ontología spinoziana construida en la Ética.

5 "En la naturaleza no se da ninguna cosa singular sin que se dé otra más potente y más fuerte. Dada una cosa cualquiera, se da otra más potente por la que aquélla puede ser destruida" (G II, p. 384; Traducción de Vidal Peña, Madrid, Editorial Tecnos, 2010). A partir de ahora E. 
los principios ${ }^{6}$. Spinoza señala el peligro de esa medida, que puede conducir al Estado a transformarse en monarquía, forma de Estado más inestable, menos perfecta, que la aristocracia $^{7}$. Es decir, menos resistente debido a su mayor debilidad interna. La única posibilidad de estabilidad vendría dada en tal situación, en principio transitoria y correspondiente a un periodo crítico de excepción, por la capacidad de la fuerza del dictador de mantenerse lo suficiente como para que el Estado no cambiara de forma. La condición técnica que hace posible dicha estabilidad consiste en subordinar el Consejo de síndicos al Consejo Supremo ${ }^{8}$, de modo que el poder esté en manos de un sujeto social ${ }^{9}$, no natural (psicológico), superando el recurso al dictator que, como vimos, presenta el riesgo de incurrir en mera monarquía. Hay que recordar que el Consejo de síndicos está formado por un grupo de patricios, elegidos con carácter vitalicio, cuya función es "vigilar que los derechos del Estado, relativos a los Consejos y a los funcionarios estatales, se mantengan intactos" ${ }^{10}$. Se trata, por tanto, de un poder judicial con capacidad para el control del poder ejecutivo. Este Consejo ha de cumplir un requisito técnico en relación con el número de sus integrantes de modo que se neutralice el doble riesgo de un consejo imperfecto por exceso o por defecto. El Estado permanecerá estable si el consejo que detenta el poder cumple esta condición, esto es, mientras el número de sus miembros sea lo suficientemente numeroso como para que sea imposible la confabulación para el delito, pero no tanto como para que puedan repartirse el Estado ${ }^{11}$. A ello se suman condiciones técnicas de edad, pago de impuestos, desempeño de cargos y el hecho de que las sentencias sean dictadas en nombre de todo el Consejo y no de sus miembros en calidad de individuos ${ }^{12}$, que van orientadas a garantizar su eternidad ${ }^{13}$, es decir, su carácter impersonal, en el que el factor psicológico, subjetivo, afectivo ha sido reducido tanto como sea posible a cero. El término aeternum ha de ser aquí definido dentro del campo categorial de lo político, que es en el que Spinoza está ejercitando el análisis del Tratado político, sin olvidar por ello que, como se precisará más adelante, descansa sobre un sistema ontológico general plasmado principalmente en la Ética. Por ello no está vinculado a noción de durabilidad en el tiempo, sino que se refiere a lo que es, dentro de la efímera condición de lo finito, ajeno a los vaivenes y sacudidas de los afectos de los sujetos humanos individuales, afectos que, lejos de quedar al margen del terreno de la política, son el verdadero material de su artesanado, pero bajo el enfoque ontológico de inercias afectivas que rebasan la mera individualidad, dada en sus variantes metafísicas formalmente más dispares pero materialmente homologables: alma personal, voluntad libre, derechos humanos, identidad propia, compromiso ideológico, etc. Los idealismos políticos de distinto signo se alimentan de este tipo de pantallas con las cuales recortar al individuo por medio de ficciones que se toman por verdades, en una pureza que la realidad material, necesariamente conflictiva y entretejida, desmiente. Esta naturaleza impersonal del poder político desvela el papel simbólico y retórico de la idea

\footnotetext{
“imperium ad suum principium restituendi" G III, p. 206 (vb).

"reipublicae salus et conservatio admodum incerta" G III, p. 208 (vb).

"syndicorum concilium concilio supremo subordinandum" G III, p. 208 (vb).

“non penes personam aliquam naturalem, sed civilem" TP, X, 2, G III, p. 210 (vb).

TP, VIII, 20, G III, p. 156 (vb).

TP, X, 2, G III, p. 210 (vb).

Ibidem.

Ibidem. Cf. S. Torres, "La presencia de Machiavelli en el Tratado Político de Spinoza”, en Revista Conatus, Filosofía de Spinoza, vol. 4, núm. 7, julio 2010, pp. 81-95. En especial, pp. 92-93.
} 
de voluntad, fantasma que oculta la necesidad del orden del $\operatorname{ser}^{14}$. La voluntad se reduce a determinaciones dadas a diferentes escalas, por lo que, política y ontológicamente, queda desactivada, es inoperante o residual. Ahí radica la clave del sustrato ontológico del Estado, que obedece, como cualquier otro modo de ser de la substancia infinita, a la compleja red de causalidad necesaria (eterna en este sentido estricto, excluida toda connotación relativa a la duración), cuyo orden no está sujeto a la capacidad cognitiva del ser humano, sino que, al revés, es la capacidad cognitiva del ser humano la que forma parte de ese orden necesario como uno de sus modos ${ }^{15}$. Se podría decir que el carácter impersonal, impermeable a voluntades subjetivas o individuales, es un caso más de la impersonalidad radical, base del materialismo spinoziano, de la secuencia necesaria de lo real. Lo que a la mentalidad humana pueda parecer irracional (la medida ontológico-especial) no lo es a la medida de la substancia infinita (la ontológico-general) ${ }^{16}$.

Esa necesidad de regresar a los principios es retomada por Spinoza implícitamente cuando se refiere al riesgo de las épocas de paz, que permiten superar el estado de barbarie y alcanzar altos grados de civilización pero que pasado ese equilibrio y al haber desaparecido el miedo como factor político de sujeción y de cohesión ${ }^{17}$, y dado que los hombres se guían más por las pasiones que por la razón, desembocan en debilidad política e inercia, en descomposición acelerada, en servidumbre por adopción de costumbres extranjeras y rendición ${ }^{18}$. La secuencia de esta degradación política recorre tres estadios que permiten establecer líneas de demarcación con las cuales diagnosticar la fase en la que un Estado se encuentra en cada caso: de la barbarie a la civilización ${ }^{19}$, y de la civilización a la decadencia ${ }^{20}$, en la que las virtudes políticas desaparecen bajo la opulencia y el ocio. La Europa del siglo XXI acaso pueda verse reflejada en este dictamen.

Es preciso recordar que Spinoza atribuye dos significados al término paz. El primero de ellos es el sentido impropio, en el cual la paz es entendida como mera ausencia transitoria de guerra y pura inercia que alienta los vicios políticos del Estado y le conducen a su disolución ${ }^{21}$. En el segundo, el sentido propio, la paz es concebida como virtud política positiva asociada a la estabilidad del Estado ${ }^{22}$, cuyo fruto es la ausencia de conflictos internos y de amenazas externas. En el párrafo citado antes, parece referirse al primero. Esa inercia que se refugia por temor en la ausencia de conflicto bélico declarado constituye mera servidumbre ${ }^{23}$.

14 E, I, prop. XXXII, G II, p. 66.

15 E, I, apéndice, G II, p. 78 ss.

16 “(... la naturaleza no está confinada a las leyes de la naturaleza humana, que tan sólo miran a la verdadera utilidad del hombre y a su conservación, sino que implica infinitas otras, que abarcan el orden eterno de toda la naturaleza, de la que el hombre es una partícula, y por cuya necesidad todos los individuos son determinados a existir y a obrar de cierta manera. Así, pues, si algo nos parece ridículo, absurdo o malo en la naturaleza, se debe a que sólo conocemos parcialmente las cosas e ignoramos, en su mayor parte, el orden y la coherencia de toda la naturaleza, y a que queremos que todas las cosas sean dirigidas según los hábitos de nuestra razón. Pero la verdad es que aquello que la razón define como malo, no es malo en relación al orden y a las leyes de toda la naturaleza, sino únicamente en relación a las leyes de nuestra naturaleza" (B. Spinoza, Tratado TeológicoPolítico, Madrid, Alianza Editorial, trad.: A. Domínguez, XVI, 191, G III). A partir de ahora TTP.

17 TP, X, 4, G III, p. 212 (vb).

18 Ibidem.

19 Ibidem.

20 Ibidem.

21 TP, V, 4, G III, p. 64 (vb).

22 Ibidem.

23 Ibidem. 
Debido a esos peligros, y al carácter pasional de la inercia de la conducta humana en sociedad, se impone la exigencia (racionalmente) política de prohibir esos vicios indirectamente, o lo que es lo mismo, renunciar a la pretensión catastrófica, por voluntarista e idealista, de que los hombres vivan según la razón (en la medida de lo humano). En su lugar, se ajusta más al orden de los asuntos políticos construir el Estado sobre principios establecidos en función de la tendencia de los sujetos a comportarse según las pasiones, de manera que se guíen según aquellas que más útiles son políticamente, las que más facilitan la estabilidad del Estado ${ }^{24}$. Dicho de otro modo, el hecho de que los hombres no se comporten racionalmente forma parte de la racionalidad de la ontología general y, en el marco de lo político, la racionalidad del Estado (como un momento o fractal ${ }^{25}$ de la ontología general) sobrepasa el plano individual, es ajena a valoración moral y se sostiene sobre su capacidad limitada de estabilidad y permanencia, de perseverancia en el ser, como cualquier otro individuo finito. La tesis central sobre la que descansa este planteamiento, y que se reproduce en el capítulo dedicado a la democracia, es la siguiente: si como en física es más fácil conducir un cuerpo en su movimiento inercial que contra él (según las leyes causales necesarias a la escala de lo físico), también a escala de lo político es más fácil y, en consecuencia resulta más estable políticamente, un Estado que conduce a las masas (verdadero material de la política $^{26}$ ) según sus pasiones, o líneas vectoriales de inercia, que contra ellas. La ley de inercia, alcanza rango ontológico en la Ética ${ }^{27}$. Así como en el esquema de pureza geométrica (virtual) de la ley de inercia de Galileo el móvil conservaría su estado - sea de reposo, esto es, de diferencia nula de velocidad con respecto al movimiento del cuerpo de referencia, sea de movimiento, esto es, de diferencia mayor que 0 con respecto al movimiento del cuerpo de referencia ${ }^{28}$ - si no actúa sobre

24 TP, X, 6, G III, p. 212 (vb).

25 Por fractal entiendo, siguiendo el modelo geométrico, la repetición a diferentes escalas del mismo patrón o estructura básica. Acaso merezca la pena el ensayo de aplicar a las distintas escalas en las que se mueve la ontología de Spinoza la noción de fractal, como el marco de líneas maestras que trazan las tendencias inerciales de los seres finitos.

26 É. Balibar, Spinoza y la politica, Buenos Aires, Prometeo Libros, 2011, pp. 137 y ss. También, Y. Yovel, Spinoza and Other Heretics. The Marrano of Reason, New Jersey, Princeton University Press, 1989, cap. 5.

27 E, III, prop. IV, G II, p. 238, y prop. VIII, G III, p. 240: "Ninguna cosa puede ser destruida sino por una causa exterior". "El esfuerzo con que cada cosa intenta perseverar en su ser no implica tiempo alguno finito, sino indefinido. Demostración: En efecto: si implicase un tiempo limitado que determinara la duración de la cosa, entonces se seguiría, en virtud sólo de la potencia misma por la que la cosa existe, que dicha cosa no podría existir después de ese tiempo limitado, sino que debería destruirse; ahora bien, eso (por la Proposición 4 de esta Parte) es absurdo; por consiguiente, el esfuerzo por el que la cosa existe no implica un tiempo definido, sino al contrario, ya que (por la misma Proposición 4 de esta Parte), si no es destruida por ninguna causa exterior, continuará existiendo en virtud de la misma potencia por la que existe ahora. Luego ese esfuerzo implica un tiempo indefinido. Q. E. D.”.

28 “(...) eliminados todos los impedimentos externos, un grave en la superficie esférica concéntrica a la Tierra será indiferente al reposo y a los movimientos hacia cualquier parte del horizonte y se conservará en aquel estado en el que habrá sido puesto. Esto es, si fuera puesto en estado de reposo, éste se conservará, y si fuera puesto en movimiento, v. g. hacia occidente, se mantendrá en el mismo. Y así por ejemplo, una nave que una sola vez hubiera recibido algún ímpetu por el mar tranquilo, se movería en torno a nuestro globo sin cesar nunca y puesto en reposo se mantendría quieta perpetuamente, si en el primer caso se pudieran eliminar todos los impedimentos extrínsecos y en el segundo no se sobreañadiese alguna causa motriz externa" (Galileo, Segunda carta sobre las manchas solares, 1612, Opere, V, pp. 134-135, citado por A. Beltrán, introducción a Diálogo sobre los dos máximos sistemas del mundo ptolemaico y copernicano, Madrid, Alianza Editorial, 2011, pp. XXXVI-XXXVII). 
él ninguna fuerza externa (eppur si muove) ${ }^{29}$, así en la ontología de Spinoza, no hay limitación interna al individuo, sino externa, por lo que su existencia cesa por una causa exterior ${ }^{30}, 31.32$. Spinoza está teorizando el barrido de las causas finales escolásticas como principios internos del ser a escala ontológico-general y de todo esencialismo, como Galileo habría contribuido a hacerlo en el plano ontológicoespecial de la física de los móviles ${ }^{33}$.

\section{La lógica de lo irracional o la política de las pasiones}

En este esquema de racionalidad duplicada por la ficción de la perspectiva humana, la libertad se identifica con la composición de fuerzas que dicen libre al movimiento de caída o inercial que no encuentra resistencia, a aquellos conglomerados de pasiones que, comportándose pasionalmente, lo hacen también políticamente, como por una sola mente ${ }^{34}$, es decir, de forma útil para el Estado, que induce o excita dichas pasiones, con independencia del grado de consciencia que los sujetos tengan de ello. El significado de libertad a escala política sólo podría entenderse partiendo de ese sustrato ontológico, substancialmente idéntico sub specie aeternitatis ${ }^{35}$. No hay modo de dominación más eficaz que el que se presenta como libertad. Sin tener presente esta lección es imposible entender las dinámicas de poder en general, ni las de la postmodernidad en particular.

El Estado aristocrático, en el que los derechos (el alma del Estado) se conservan, es considerado aquí por Spinoza como eterno (o necesario en el sentido indicado antes), es decir, a salvo de infecciones (vicios) internas ${ }^{36}$, por lo que sólo perecerá por causas externas ${ }^{37}$. Esos derechos han de apoyarse en la razón y en lo que Spinoza denomina "communi hominum affectu", el común afecto de los hombres. La razón por sí sola, sin la fuerza de las pasiones, es estéril políticamente. Sólo se impondrá como afecto más potente, no por su pura condición racional. Así, en cierto paradójico modo, lo racional sólo triunfa dejando de ser racional, imponiéndose como pasional $^{38}$.

29 Según S. Drake, Galileo at Work: His Scientific Biography, Chicago, Dover Phoenix Editions, 1978, la frase aparece en 1643 o 1645 en un cuadro atribuido a Murillo o a un pintor de su escuela. Sobre la revisión del caso Galileo y las verdaderas causas de su proceso, su atomismo antes que su heliocentrismo, cf. M. Artigas, R. Martínez, R. S. William, "Nueva luz en el caso Galileo", en Anuario de Historia de la Iglesia (Facultad de Teología, Universidad de Navarra), 12 (2003), pp. 159-179.

30 "Todo cuerpo, o se mueve, o está en reposo" (E, II, axioma I, G II, p. 100).

31 "Los cuerpos se distinguen entre sí en razón del movimiento y el reposo, de la rapidez y la lentitud, y no en razón de la substancia" (E, II, lema I, G II, p. 128).

32 "Un cuerpo en movimiento o en reposo ha debido ser determinado al movimiento o al reposo por otro cuerpo, el cual ha sido también determinado al movimiento o al reposo por otro, y éste a su vez por otro y asi hasta el infinito" (E, II, lema III, G II, p. 128).

33 En lo político, esto se plasma en estas fórmulas que Spinoza emplea aquí, en TP, X, 6, G III, p. 212 (vb): “indirecte prohibenda" y "ut subditi magis sponte, quam lege coacti suum officium faciant".

34 "una veluti mente".

35 “(...) los hombres deben ser guiados de forma que les parezca que no son guiados, sino que viven según su propio ingenio y su libre decisión” (TP, X, 8, G III, p. 214 [vb]).

36 TP, X, 9, G III, p. 216 (vb).

37 Ibidem.

38 "Nada de lo que tiene de positivo una idea falsa es suprimido por la presencia de lo verdadero, en cuanto verdadero" (E, IV, prop. I, G II, p. 384). Cf. Yovel, op. cit., p. 133). 
En Spinoza, la racionalidad humana no es la rúbrica o el vestigio de la Racionalidad Divina. Como en los escolásticos, la razón no es propiamente un atributo de Dios. La razón exige cadenas de argumentos, una secuencia operatoria ajena a una Conciencia infinita. Es silogística, dialéctica y procesual, no inmediata. El conocimiento que el Absoluto tendría de la realidad sería intuitivo, no deductivo, inmediato, no mediado ${ }^{39}$. El equívoco idealista resulta del uso del mismo término para dos potencias inconmensurables: la racionalidad ontológico general, que podríamos asimilar al orden necesario de lo real, y la racionalidad humana, como una peculiaridad particular a escala ontológico especial ${ }^{40}$. La razón, a escala de lo humano, es sólo un momento de la racionalidad substancial del orden de la naturaleza. Lo que a la perspectiva humana resulta irracional, por pasional, no lo es a la escala ontológica de la cadena múltiple causal que constituye el orden y conexión de las cosas, que es el mismo orden y conexión de las ideas. Los afectos y lo imaginario siguen ese orden de modo tan implacable (racional) como la razón. Así, tan racional es en política la estupidez y el predominio de lo afectivo y lo imaginario, que es en lo que consiste la sumisión ${ }^{41}$, como lo racional, mucho más excepcional dentro de ese esquema de racionalidad que podemos representar por medio de la ley de inercia. Lo racional a escala ontológico-general impone la excepcionalidad de lo racional a escala ontológico-especial. La Substancia infinita, como orden necesario y eterno de la realidad, se da a escala del entendimiento humano como extensión, es decir, bajo los parámetros de reposo, movimiento, choque, tensión, velocidad, fuerza, distancia, posición, etc. Y como pensamiento se da a escala del entendimiento humano en dos sentidos: como modi cogitandi (humanos), por tanto, los contenidos mentales de los sujetos humanos, y como modi cogitationis (o pensamiento "en Dios"), esto es, la racionalidad de lo real, que se dispara más allá del plano de lo humano, pero que por su capacidad, los sujetos dotados de entendimiento pueden reconstruir excepcionalmente; es decir, conocer, dentro de campos categoriales delimitados y, que, a modo de fractales, acatan o cumplen ese orden necesario ontológico-general ${ }^{42}$. Así entendida, la racionalidad exige concebir las cosas como necesarias, no como contingentes ${ }^{43}$. Y, de modo análogo a como el cuerpo que tiende a conservar su estado es considerado libre por no verse afectado por fuerzas externas que modifiquen su dirección vectorial (sea de reposo, sea de movimiento), el Estado Absoluto, esto es, indiviso, es el que más capacidad de permanencia y estabilidad posee y, por tanto, es eterno, es decir, inercial (y necesario) hasta que una fuerza o causa externa actúe contra su estabilidad ${ }^{44}$. Tanto más estable y, por tanto, potente, será ese Estado cuanto

39 "ni el entendimiento ni la voluntad pertenecen a la naturaleza de Dios" (E, I, prop. XVII, esc., G II, p. 46).

40 "La mayor parte de los que han escrito acerca de los afectos y la conducta humana, parecen tratar no de cosas naturales que siguen las leyes ordinarias de la naturaleza, sino de cosas que están fuera de ésta. Más aún: parece que conciben al hombre, dentro de la naturaleza, como un imperio dentro de otro imperio [imperium in imperio]. Pues creen que el hombre perturba, más bien que sigue, el orden de la naturaleza [hominem naturae ordinem magis perturbare, quam sequi], que tiene una absoluta potencia sobre sus acciones y que sólo es determinado por sí mismo" (E, III, prefacio, G II, p. 218).

41 La ocurrencia presuntamente rebelde de ciertos lemas de mayo del 68 ("La imaginación al poder") se revela ingenuamente conservadora en este punto. El análisis teórico político de Spinoza muestra hasta qué medida la imaginación siempre estuvo en el poder, pues es uno de sus mecanismos de producción de sumisión más funcionales.

42 Cf. V. Peña, intr. a la E, pp. 35 y ss; pp. 53-55; cf. G. Bueno, Ensayos materialistas, Madrid, Taurus, 1972, pp. 438-439.

43 E, II, prop. XLIV, G II, p. 188.

44 TP, X, 10, G III, p. 218 (vb). 
menos riesgo de descomposición interna padezca. El Estado descrito estaría a salvo, gracias a la fuerza de la ley, vigente en función de los mecanismos técnicos reseñados, de perecer por su propia condición interna, por lo que su destrucción sólo puede tener lugar a causa de una fuerza exterior, según el axioma ontológico que impone fecha de caducidad a todo ente finito y temporal. Y como esquema originario se acopla a toda forma de Estado, según distintas gradaciones, aunque es la democracia la que lo cumple con mayor perfección. Esas gradaciones oscilan en función de la balanza entre gobierno y multitud y, dentro de cada uno de esos campos de fuerza, entre actividad y pasividad ${ }^{45}$.

\section{Obediencia al Estado por consenso}

Es costumbre referirse al Tratado político y, en particular, a su último capítulo, como una defensa de la democracia. Sin embargo, aun en el caso de que se admita semejante dictamen, cabe preguntarse qué se entiende por democracia y qué se entiende por defensa de ella. Para afrontar este inexcusable reto preliminar resultará útil recurrir a una somera reconstrucción genealógica del término y al uso que el propio Spinoza le otorga en otras partes de su obra.

En el parágrafo 74 del capítulo V del Tratado teológico-político, no aparece explícitamente el vocablo democracia pero Spinoza enumera, a continuación, tres enseñanzas que pueden deducirse a escala de lo político de la naturaleza humana, proclive a guiarse por las pasiones más que por la razón. Si se diera el caso de que la naturaleza humana fuera racional, esto es, que los hombres sólo desearan lo que la razón les dicta ${ }^{46}$, la política consistiría en la simple información de lo que técnicamente es más útil para la sociedad, lo cual sería automáticamente realizado en una suerte de democracia perfecta basada en la identidad entre saber y poder, entre razón y acción, entre gobierno y multitud. Semejante hipótesis está neutralizada completamente por el sistema ontológico de Spinoza. Es un imposible con el que soñarán ilustrados y utopías diversas, con resultados conocidos. Por eso, en la primera de estas lecciones, la posibilidad que admite Spinoza se mueve entre el poder detentado de forma colegiada ("collegialiter") por toda la sociedad, si es posible ("si fieri potest"), de modo que todos se obedezcan a sí mismos por obligación, $\mathrm{y}$, por otro lado, el poder detentado por una naturaleza humana superior o, lo que es más preciso por no caer en la tentación de lo imposible, convencer de tal condición al vulgo. Por collegialiter parece referirse a consenso, dada la expresión con la que más adelante precisa esta idea y, por tanto, no impuesta por una parte de la sociedad sobre otra, sino impuesta por toda ella sobre toda ella, lo que verdaderamente podría considerarse Estado Absoluto y, como libre de toda dependencia ajena, democracia. Pero ¿no deja eso a la democracia en el terreno de lo meramente conceptual? ¿No sería, como a nuestro juicio sucede en la República platónica, una ficción teórica, una geometrización de lo político, que permita medir por contraste el grado de independencia, libertad y seguridad y, en última instancia, de estabilidad de los Estados realmente existentes, un artificio genealógico con el que reconstruir la secuencia de las dinámicas materiales de poder? Para cumplir esa segunda posibilidad, he aquí la segunda lección,

${ }^{45}$ Cf. S. Torres, op. cit., p. 93.
46 Cf. Y. Yovel, op. cit., p. 135 
deducida more geometrico en el sentido indicado: es más eficiente en la práctica política conducir (o mantener en su estado: "retineantur") a los sujetos por medio de la esperanza que del miedo. Esta sería la clave que permite entender el consenso no en su habitual carácter legitimador, sino como mecanismo político que permite que las leyes del Estado sean obedecidas con menor oposición, con menor grado de resistencia, lo que contribuye a su mayor estabilidad. Con respecto a la tercera lección, Spinoza hace referencia a la obediencia, entendida como el cumplimiento de las órdenes del que tiene el mando, por lo que no cabe considerarla como tal en una sociedad en la que el mando estuviera en manos de todos y sus leyes sancionadas por común consenso ${ }^{47}$. En ese caso, el pueblo sería libre al actuar por su propio consenso (obedeciendo al Estado se obedecerían a sí mismos) y no por el de otro. Como quedó reflejado en el comentario al capítulo X del Tratado político, no veo que pueda ser entendida aquí la libertad de modo positivo más que por analogía con la noción de caída libre en la física de Galileo y sobre la base de la ontología de la Ética. Esto significa que el pueblo es libre no por ser sujeto de una voluntad (ni siquiera general, al modo de Rousseau) o libre arbitrio (al modo escolástico-cartesiano), sino mientras siga su propia esencia y no la de otra cosa. Por esencia ha de entenderse su perseverancia en el ser, su movimiento inercial de resistencia al cambio de estado. Libre es libre de agentes externos que modifiquen su naturaleza. No hay elección ni voluntarismo. Tan necesario es caerse libremente al vacío como ser empujado por una fuerza exterior. Y tan libre es el pueblo que se dirige a su propia destrucción como esclavo el que es sometido por un agente externo y perdura ${ }^{48}$. Lo que sucede es que el consenso o poder colegiado suele reducir las resistencias a las leyes más que cuando éste falta.

Siguiendo la argumentación precedente, en Tratado teológico-político, XVI, 193, Spinoza da ahora el nombre de esa forma de Estado en la que aparece la noción de pacto, extremadamente problemática desde el enfoque inequívocamente materialista de la ontología spinoziana. Si la noción de voluntad libre queda excluida ontológicamente, sólo cabe aceptarla por analogía y entendiendo que ha de tener un significado preciso a escala de lo político, distinto del tradicional. Es como si Spinoza concediera el uso de determinados vocablos por ser comunes al lenguaje de la época, como afirma explícitamente cuando se refiere a los afectos en Ética, III, a cambio de evacuar su contenido, reventando su uso acrítico y desplazándolos hacia los significados que el método geométrico de su ontología impone. La voluntad política, como la libertad o el pacto, sería, por tanto, un concepto técnico en el que la carga metafísica del término en su uso tradicional habría sido disuelta. Cuando en este pasaje Spinoza habla de transferir el derecho a la sociedad está hablando del poder de cada uno, que no es nada en sí mismo sino incrustado y determinado por la urdimbre de relaciones y conflictos en la cual cada cosa está recortada, en la cual cada cosa es lo que es, con respecto a cada campo categorial: como cuerpo físico, como cuerpo político, que es a lo que se refiere el autor en todo momento con naturaleza (Natura naturata). Por eso, la definición que aquí se propone de democracia es el derecho de una sociedad en la cual los sujetos que la componen poseen colegiadamente el poder. Pero, dado que, en todo caso, tanto derecho se posee cuanto poder y, por tanto, ese derecho no emana de una instancia primigenia ajena a la causación material que envuelve y determina cada individuum finito, lo específico de la definición ha de estar en otro aspecto y

\footnotetext{
47 "leges ex communi consensu sanciuntur".

48 Cf. TTP, XX, G III, p. 241.
} 
no en éste, que es común a todo cuanto existe. Así, pues, es en el factor técnico del carácter consensuado o colegiado en el que radicará su condición de democracia y, según hemos indicado, su potencia política reside en reducir las fricciones que el cumplimiento del poder genera. Pero lo que tal vez queda sin especificar sean los mecanismos concretos que hagan posible ese consenso por el que la democracia se definiría. En todo caso, de ello se deduce que la libertad democrática se basa en la obediencia, por consenso, a la suma potestad del Estado ${ }^{49}$.

En este capítulo XVI (191) del Tratado teológico-político, Spinoza ha combatido el antropomorfismo que consiste en tomar como irracional lo que no concuerda con la perspectiva limitada de lo humano. No hay falta de lógica en la realidad. Lo irracional es sólo una distorsión del enfoque limitado del sujeto que pretende estudiar las cosas, enfoque que no puede abarcar el conocimiento completo de la cadena de causalidad múltiple de lo real. La peculiaridad de lo humano consiste en tener la capacidad restringida de la racionalidad, capacidad nublada, sin embargo, por la causación material afectiva de su subjetividad, origen de la ilusión de la libertad y de la irracionalidad de lo que no es humano. Del mismo modo, en 194, en el Estado, como un microcosmos a escala de la substancia infinita, como un fractal del orden necesario de lo real, lo racional es obedecer sus leyes, con independencia de que éstas parezcan absurdas a la percepción humana, esto es, irracionales ${ }^{50}$.

A continuación, expone la virtud del Estado democrático, que consiste en ser más inmune al riesgo de irracionalidad de las sumas potestades, es decir, a que, en función de sus condiciones técnicas, como son el número de sus integrantes, que minimiza el riesgo de acordar medidas contrarias al bien común, y su finalidad política, es más resistente y tiende a perdurar más. En relación con la libertad política, que sería la base de este modelo de Estado, Spinoza define lo que entiende por obediencia, y la diferencia entre esclavo y súbdito en Tratado teológico-político ${ }^{51}$. De modo que la línea de demarcación que separa servidumbre de obediencia se encuentra en el bien común como función política del Estado. El criterio, como puede apreciarse, es estrictamente político, por lo cual no puede entenderse si no es desde el prisma del Estado y de su estabilidad. La obediencia a las leyes del Estado constituye virtud política y con ellas se tiende a la cohesión del mismo. Por ello, en tanto que más resistente, esta forma de Estado es la más libre y la más natural ${ }^{52}$. Pero ¿qué puede querer decir esto? De nuevo, natural en este contexto adquiere un significado polí-

49 “(...) estamos obligados a cumplir absolutamente todas las órdenes de la potestad suprema, por más absurdas que sean, a menos que queramos ser enemigos del Estado y obrar contra la razón, que nos aconseja defenderlo con todas las fuerzas. Porque la razón nos manda cumplir dichas órdenes, a fin de que elijamos de dos males el menor" (TTP, XVI, G III, p. 194).

50 "Por último, esta doctrina es también de no poca utilidad para la sociedad civil, en cuanto enseña de qué modo han de ser gobernados y dirigidos los ciudadanos, a saber: no para que sean siervos, sino para que hagan libremente lo mejor" (E, II, prop. XLIX, esc., G II, p. 216). El conocimiento permite al sujeto, en una medida siempre limitada, gobernarse a sí mismo, es decir, ser dirigido por esa potencia, la racionalidad de estirpe geométrica (filosófica), que no es propiedad exclusiva de nadie. $\mathrm{O}$, más precisamente, adecuarse a su secuencia necesaria: “(...) son buenos

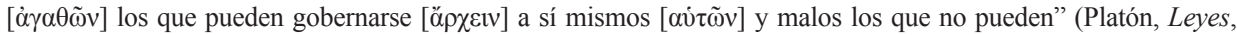
Madrid, Centro de Estudios políticos y constitucionales, 1999, edición bilingüe, 644b); "Jenócrates, el discípulo de Platón, veía la esencia de la filosofía en que educaba al hombre enseñándole a realizar voluntariamente lo que la masa sólo realiza bajo la coacción de la ley" (W. Jaeger, Paideia, Madrid, FCE, 2004, p. 721).

51 "Esclavo es quien está obligado a obedecer las órdenes del señor, que sólo buscan la utilidad del que manda; hijo, en cambio, es aquel que hace, por mandato de los padres, lo que le es útil; súbdito, finalmente, es aquel que hace, por mandato de la autoridad suprema, lo que es útil a la comunidad y, por tanto, también a él” (TTP, XVI, II, p. 195).

52 TTP, XVI, G III, p. 195. 
tico preciso que elimina las connotaciones naturalistas convencionales. Natural no puede querer decir nada relativo a Ley natural en sentido tomista o equivalente a Gracia divina por suplencia en sentido rousseauniano o al sistema más justo según una suerte de Justicia universal pre-política. Sólo se puede entender el carácter "más natural" ("maxime naturale") del Estado democrático como el más racional a escala ontológico-especial por acomodarse con menos resistencias a la racionalidad necesaria de la ontología general ${ }^{53}$. O, dicho de otro modo, la racionalidad política del Estado, entendida como la capacidad de ajustarse con los medios más adecuados al bien común de toda la sociedad y, por ello, a mantener el poder y, de ese modo, hacer duradera la composición entre sus partes, significa la capacidad para seguir menos traumáticamente el orden necesario de lo real. ¿Cuál sería, entonces, el Estado menos natural? Según parece, aquel menos estable o duradero por deficiente o frágil composición entre sus partes, por estar política e institucionalmente mal soldadas, $\mathrm{y}$, por tanto, el más sometido a fuerzas externas que obligan a que siga el orden necesario de lo real de modo traumático con respecto a sus integrantes y a él mismo como conjunto, tanto en intensidad como en frecuencia, como sugiere la fórmula de Séneca ${ }^{54}$. Así pues, súbdito es el que obedece a la autoridad si ésta gobierna con vistas al bien común. Esclavo es el que obedece al que manda cuando éste gobierna para su propia utilidad. Esta condición es común a las tres modalidades de Estado, en función del criterio cuantitativo del que detenta el poder ${ }^{55}$. Por eso, las sumas potestades no pueden cometer injuria pues todo les está permitido por derecho, esto es, por poder ${ }^{56}$. Esta obediencia a las sumas potestades, que, como vemos, no se opone sin más a la libertad política del Estado, conduce a la posibilidad de dirigir e, incluso, producir determinada mentalidad ${ }^{57}$.

Sin embargo, Spinoza no concibe la posibilidad de un poder total(itario) sobre las mentes. El poder nunca es tan absoluto, esto es, indiviso y a salvo de la descomposición de las partes que constituyen la relación en que se basa, como para penetrar

53 "De aquí se sigue que el hombre está sujeto siempre, necesariamente, a las pasiones, y que sigue el orden común de la naturaleza, obedeciéndolo, y acomodándose [accommodare] a él cuanto lo exige la naturaleza de las cosas" (E, IV, prop. 4, corolario). La idea que presenta los procesos materiales, sin excluir los que tienen a los humanos como agentes, acoplándose al orden de la realidad, aparece ya en Maquiavelo en carta a Pier Soderini, 13-21 septiembre 1506 (traducción de J. M. Forte, Epistolario privado, Madrid, Esfera de los Libros, 2007, p. 109): "Quien fuese tan sabio que conociera los tiempos y el orden de las cosas y se acomodase a ellas, tendría siempre buena fortuna" ("chi fussi tanto savio che conoscessi e tempi et l'ordine delle cose et adcomodassisi ad quelle, harebbe sempre buona fortuna"). Según nuestra hipótesis, que sigue la línea interpretativa de G. Bueno en $L a$ Metafísica presocrática, esta propuesta teórica está prefigurada cuanto menos ya en el sistema de Platón y su teoría de las formas, que son los carriles o vetas a través de los cuales se dibuja la trama de conexiones o el mapa ontológico de lo existente, como pluralidad discontinua que no puede reducirse a un único principio ni tampoco a la disolución absoluta (ad infinitum) de los entes.

54 "violenta nemo imperia continuit diu; moderata durant" (Troades, II, 258-9. Citada por Spinoza en TTP, XVI, G III, p. 194; XVIII, G III, p. 224; XX, G III, p. 240).

55 TTP, XVI, G III, p. 195.

56 TTP, XVI, G III, p. 196.

57 "Por otra parte, aunque no es posible mandar sobre las almas como sobre las lenguas, también las almas están de algún modo bajo el mando de la suprema potestad, ya que ésta puede lograr, de muchas formas, que la mayor parte de los hombres crean, amen, odien, etc., lo que ella desee. Por eso, aunque estas acciones no son realizadas directamente por orden de la potestad suprema, muchas veces, sin embargo, como lo acredita ampliamente la experiencia, son hechas por la autoridad de su poder y bajo su dirección, esto es, por su derecho. Por consiguiente, podemos concebir, sin contradicción intelectual [intellectus repugnantia] alguna, que haya hombres que sólo en virtud del derecho del Estado creen, aman, odian, desprecian y son arrastrados por cualquier pasión" (TTP, XVII, G III, p. 202). 
todos los elementos y aspectos de la sociedad o cuerpo del Estado ${ }^{58}$. Sin duda, el siglo XX queda aún muy lejos histórica, política, tecnológica y conceptualmente.

Tal como se indicó, Spinoza presenta la hipótesis de la inversión genealógica de las formas de Estado ${ }^{59}$. La secuencia convenida, según este análisis, queda invertida, de modo que se regresa a la democracia en lugar de culminar en ella. Esta forma de Estado es considerada, por lo tanto, como origen conceptual, más que histórico o cronológico, en el sentido de que es la de mayor estabilidad. Spinoza alude, en el Tratado teológico-político, al caso histórico del Estado de los hebreos, originariamente una democracia, una vez liberados, tras su salida de Egipto, del poder del Faraón para "instaurar un nuevo derecho y ocupar las tierras que quisieran"60. Así, la democracia cabría entenderla según el criterio de la cesión de los derechos de todos los miembros del grupo, y no de una parte de ellos a otros, devenida en teocracia ya que se adoptó la medida de ceder esos derechos sin restricción política (naturales) sólo a Dios, en lugar de a uno o a varios hombres, siguiendo el consejo de Moisés. Sin embargo, Spinoza precisa que la denominación de teocracia es más una formalidad que una realidad material, pues el ejercicio político de los derechos permanecía en manos de los que los habían transferido directamente ${ }^{61}$ a una instancia no humana. De hecho, en tal situación se puede afirmar que "en virtud de este pacto, permanecieron absolutamente iguales y que todos tenían el mismo derecho de consultar a Dios, de aceptar las leyes e interpretarlas, y que todos conservaban por igual la plena administración del Estado". La democracia primigenia queda abolida, sin embargo, cuando Moisés es requerido como intermediario entre la Voz de Dios y los oídos del Pueblo, por el temor de Dios, según se desprende del relato bíblico que Spinoza interpreta, acaso por la necesidad de sobrevivir en el desierto. En ese acto, sus derechos fueron entregados completamente a Moisés, dueño a partir de ese momento del poder de recibir, interpretar, trasmitir e imponer los mandatos divinos, juez supremo fuera de la posibilidad de ser juzgado, por encima de la ley. Al mismo tiempo, los sujetos que habían cedido esos derechos, habían cedido automáticamente en ese acto su derecho a elegir el sucesor de Moisés, derecho que sólo a él pertenecía. Pero Moisés no eligió un sucesor con las funciones que tenía él, lo que hubiera constituido un modelo monárquico, sino que "entregó a sus sucesores un Estado que debía ser administrado de tal forma, que no pudo denominarse ni popular ni aristocrático ni monárquico, sino teocrático" ${ }^{2}$, debido a que designó a Aarón y a los levitas como intérpretes de las leyes, y a Josué como depositario del gobierno del Estado. En el caso de que uno de ellos hubiera encarnado ambos poderes, el modelo resultante sería una monarquía. El dictamen de Spinoza es que Moisés "eligió para el Estado administradores, no dominadores"63, y nombró un Consejo supremo compuesto por jueces, encargado de esa función de administración. De ahí que, a la muerte de Moisés, nadie detentara el poder supremo ${ }^{64}$. La vigencia de esta forma de

58 "Aunque, por lo dicho, nosotros concebimos con bastante amplitud la potestad y el derecho del Estado, nunca se logrará que exista uno tan poderoso, que quienes están a su mando, tengan poder absoluto sobre todo lo que quieran" (TTP, XVII, G, III, p. 203. Cf. sobre esto, TP, IV, 4, G III, p. 54 [vb] y 6, G III, p. 60 [vb]).

59 TP, VIII, 12, G III, p. 148 (vb).

60 TTP, XVII, G III, p. 205.

61 "nullo expresso mediatore".

62 TTP, XVII, G III, p. 208. También, p. 212.

63 TTP, XVII, G III, p. 209.

64 "no todo dependía de la decisión de un hombre, ni de un consejo, ni del pueblo, sino que unas cosas eran incumbencia de una tribu y otras, con igual derecho, de las demás tribus" (TTP, XVII, 2G III, p. 11). 
Estado duró mientras se pudo mantener la obediencia de los súbditos al Estado gracias a la obediencia a Dios ${ }^{65}$, pero en cuanto se entró en una fase de cambios, lujo y pereza, la descomposición del Estado fue inevitable. El pacto con Dios se rompió y fue reclamado un rey mortal, con lo cual desplazar el centro del poder del templo al palacio, y convertir a las tribus en conciudadanos en virtud del derecho regio y no del divino. La consecuencia de ello fue "la ruina total del Estado"66. Sin la invisibilidad trascendente de un poder supremo, el poder de los sujetos mortales estaba herido de una precariedad política tal que resultó incapaz de detener la descomposición interna. Acaso se pueda aludir a otro caso histórico excepcional en el que encontrar, por analogía, el carácter primigenio de ese modelo político dado en condiciones materiales concretas, muy poco frecuentes: el de los primeros peregrinos en América del Norte antes de la fundación de los Estados Unidos ${ }^{67}$. El tercer ejemplo que podría aducirse, con el que cerrar el círculo, es el del actual Estado de los hebreos, Israel, con las precisiones históricas que sería exigible establecer.

\section{Democracia teocrática}

En el capítulo XVIII del Tratado teológico-político, no aparece el vocablo democracia pero sí la expresión "reino o gobierno del pueblo", insistiendo en la tesis del carácter originario y más estable de esa modalidad política. Se sostiene que el cambio de la primera forma del Estado a la monarquía es causa de su inestabilidad e, incluso, que las leyes permanecen incorruptas mientras dura. El estado democrático es definido aquí como aquel en el que "todos deciden, de común acuerdo, vivir solamente según el dictamen de la razón" $"$. Según esto, la democracia sería la forma de Estado más racional. Este marco acotado de lo real que es el Estado político queda diferenciado de lo que llama estado de naturaleza en virtud del criterio de la confrontación razón-apetito. Por decirlo abiertamente, si por Dios entendemos el orden necesario de la realidad, la trama ciega que ni conoce ni quiere, en el campo concreto de la política el mejor modelo de gestión del poder, es decir, el que con menos resistencias se encuentra en su funcionamiento, es el que obedece los mandatos de la razón a escala de lo humano, de lo que contribuye mejor a su utilidad, a su salud, lo cual implica obedecer los mandatos del Dios que es el orden geométrico-ontológico. Así, la democracia como gobierno de la racionalidad será el gobierno de lo divino, una teocracia ontológica. La democracia es teocracia ${ }^{69}$. El gobierno del Pueblo es el gobierno de Dios. El pacto social ocupa el lugar del pacto con Dios. Ambos pactos son, por ello, ficciones. Y es teocracia en su doble variante: sana o patológica. En el sistema spinoziano, la democracia, como forma estable de Estado, sería teocrática porque constituye un calco más preciso, al ser más lúcido, de la racionalidad ontológico-general. Obedecer el orden que se conoce. En términos concretos, depositar el poder en Dios o en el Pueblo, es decir, fuera del alcance de algún sujeto en particular, mortal, o de algunos, implica, tendencialmente, racionalizarlo en el sentido de hacerlo en lo posible impersonal, eterno, ajeno a duración. La demagogia, o la variante

\footnotetext{
65 TTP, XVII, G III, p. 216.

66 TTP, XVII, G III, p. 219.

67 Cf. A. De Tocqueville, La democracia en América.

68 TTP, XIX, G III, p. 230.

69 Cf. É. Balibar, op. cit., p. 64.
} 
defectuosa de esa forma de Estado, sería teocrática en cuanto tiende a sustituir a Dios por el Pueblo, otorgando a esta nebulosa metafísica la legitimidad del poder, dirigiendo a la sociedad hacia su destrucción de manera acelerada por ignorancia del orden que pretende subvertir o modificar. En tal caso no habría racionalización del poder, sino ceguera, y el poder no sería impersonal, sino suprapersonal ${ }^{70}$. La diferencia establecida por Spinoza entre un estado de naturaleza y un Estado político no reside en la racionalidad del segundo, como si estuviera ausente del primero. No hay realidad que no esté sometida a la racionalidad ontológico general de la substancia infinita. La diferencia consiste en que en el Estado político se concede más derecho a la razón (humana) que a los deseos, mientras que en la naturaleza el derecho se reduce a la potencia de cada uno, sea pasional o racional, bajo la perspectiva del entendimiento humano. El derecho político responde a una operación de racionalidad a la escala de lo humano y, por tanto, con vista a la utilidad política, medida para la cual se exige esa cesión de derechos o poderes naturales. Sólo de este modo parece que pueda entenderse la mayor funcionalidad política de un Estado dirigido racionalmente, es decir, orientada a perdurar en el tiempo. Como recalca el propio Spinoza aquí una vez más, no hay derecho, justicia, injusticia, pecado o vicio fuera del Estado (de derecho). Por lo que cabe extender la tópica denominación de Estado de derecho, invocada retóricamente como definitoria de las democracias, a toda forma de Estado, como recinto operativo en el que una estructura de poder otorga y gestiona los derechos. No hay, en consecuencia, derechos humanos, como si estos pudieran ser emitidos o concedidos graciosamente por una naturaleza humana pura o angelical, que sobrevolara los Estados realmente existentes, previa o independiente de ellos. Todo derecho es político. No hay derecho sin Estado.

El análisis que acabamos de ofrecer encuentra respaldo explícito en el último capítulo del Tratado teológico-político, donde la expresión "Estado democrático" aparece dos veces. En la primera (Tratado teológico-político, XX, 239) es contrapuesto a monárquico. En la segunda (Tratado teológico-político, XX, 245), se define el criterio técnico, propio del campo de lo político pero sostenido por el sistema ontológico de Spinoza, que marca el carácter específico de esa modalidad de poder ${ }^{71}$. El Estado democrático, fractal de la Natura naturata, es el que más se ajusta a las coordenadas de la Natura naturans, el "más natural", por tanto, en este estricto sentido. Por eso, la libertad es concebida como factor técnico que permite el sometimiento a la racionalidad política del Estado y, por extensión, su perdurabilidad. El procedimiento de aplicabili-

70 "Y por eso, para que la religión revelada a través de los profetas también tuviera fuerza de derecho entre los hebreos, fue necesario que cada uno de ellos renunciara a su derecho natural y que todos, de común acuerdo [communi consensu], decidieran obedecer tan sólo a aquello que les fuera revelado por Dios a través de los profetas; exactamente de la misma forma que se hace, según hemos visto, en el Estado democrático, donde todos deciden, de común acuerdo [omnes communi consensu deliberant], vivir solamente según el dictamen de la razón [ex solo rationis dictamine vivere]" (TTP, XIX, G III, p. 230).

71 "Por consiguiente, para que se aprecie la fidelidad y no la adulación y para que las supremas potestades mantengan mejor el poder, sin que tengan que ceder a los sediciosos, es necesario conceder a los hombres la libertad de juicio y gobernarlos de tal suerte que, aunque piensen abiertamente cosas distintas y opuestas, vivan en paz. No cabe duda de que esta forma de gobernar es la mejor y la que trae menos inconvenientes, ya que está más acorde con la naturaleza humana [cum hominum natura maxime convenit]. Efectivamente, en el Estado democrático (el que más se aproxima al estado natural), todos han hecho el pacto, según hemos probado, de actuar de común acuerdo, pero no de juzgar y razonar. Es decir, como todos los hombres no pueden pensar exactamente igual, han convenido en que tuviera fuerza de decreto aquello que recibiera más votos, reservándose siempre la autoridad de abrogarlos, tan pronto descubrieran algo mejor. De ahí que cuanta menos libertad se concede a los hombres, más se aleja uno del estado más natural y con más violencia, por tanto, se gobierna” (TTP, XX, G III, p. 245). 
dad que ese criterio exige en un contexto en el que la unanimidad absoluta es imposible (o es homicida, caso que repugna a la mentalidad de Spinoza, motivo por el cual no contempla esta posibilidad, como hemos visto antes ${ }^{72}$ ), es el sufragio, que otorga a la mayoría de votos "fuerza de decreto". Infringir estos criterios técnicos supone tener que gobernar con mayor grado de violencia y poner en riesgo la estabilidad del Estado. Todo fundamentalismo democrático, todo moralismo idealista, que sueña una fuente de legitimidad pura y de bondad absoluta de la que la democracia se nutre per se, queda reventado por el análisis materialista de Spinoza. De ahí que su teoría política tenga acaso mayor campo de aplicabilidad analítica en el estudio de los Estados del siglo XX. $\mathrm{O}$, en todo caso, arroja luz sobre la niebla con la que la retórica inerte y perezosa de lo políticamente correcto cubre las dinámicas materiales de poder.

En el Tratado político, antes del capítulo XI, aparece el vocablo en uno de los capítulos dedicados a la monarquía. Ahí, siguiendo la línea argumental que estamos presentando, Spinoza recalca la estabilidad natural de la democracia frente a la monarquía. Mientras que la fuerza de ésta es más patente en situaciones convulsas, la de la democracia se muestra con mayor poder y funcionalidad en la paz ${ }^{73}$.

Por último, la referencia a la democracia aparece dos veces en el capítulo VIII, 1 y 12, del Tratado político, dedicado a la aristocracia. La primera de ellas, para precisar el criterio técnico que la diferencia de la aristocracia. La segunda, para referirse a la inversión genealógica de las formas de Estado de la que ya hemos hablado. Con respecto a la primera de estas cuestiones, Spinoza establece como condición del gobierno aristocrático el estar compuesto por "varios elegidos de la multitud" ", a los que denomina patricios. No será imprudente insistir en el carácter electivo y selectivo de los patricios como depositarios del poder del Estado en esa modalidad. El origen de los que detentan el poder en la democracia, por el contrario, parece tener cierto cariz indiscriminado. La pertenencia a un territorio por la vía de nacimiento o por la vía dinástica, familiar, tribal, será el factor de decisión en la democracia ${ }^{75}$. Queda descontado, por lo tanto, el componente cuantitativo o numérico hasta el punto de que, aun en el supuesto teórico de que "toda la multitud" fuera elegida para ejercer el poder, es decir, que todos fueran incluidos dentro de la categoría de patricios, el Estado sería aristocrático.

Además, Spinoza incluye dos referencias al Estado absoluto en este capítulo, que queda definido como el Estado en el que Consejo y multitud son lo mismo, o expresado en términos numéricos, el Consejo es tan numeroso que abarca la totalidad de la multitud. El carácter selectivo y lo suficientemente amplio del Consejo de patricios en la aristocracia asegura la tendencia a gobernar más según la razón que las pasiones. Por esto, justamente, hay que insistir en que la diferencia en relación con la democracia no es tanto que ésta sea el "gobierno de la razón", en sentido absoluto, sino que radica más bien en criterios de racionalidad técnica, entre los que cabe incluir factores de orden cuantitativo, como estamos viendo ${ }^{76}$. De hecho, en la primera

72 TTP, XVII, G III, p. 201; XX, G III, p. 239; TP, IV, 4, G III, p. 56 (vb).

73 "la característica principal del Estado democrático consiste en que su virtud es mucho más eficaz en la paz que en la guerra” (TP, VII, 5, G III, p. 100 [vb]. Cf. también TP, VII, 25, G III, p. 120 [vb] y TTP, XVIII, G III, p. 221 ss.).

74 TP, VIII, 1, G III, p. 134 (vb).

75 Ibidem.

76 TP, VIII, 3, G III, p. 136 (vb). También, 4, 5 y 6. Cf. A. Negri, El poder constituyente, Madrid, Libertarias/ Prodhufi, 1994, I, 3, que señala con acierto la diferencia e, incluso, la confrontación entre Estado Absoluto y Estado totalitario. Sin embargo, se sirve de ella para entregarse a un maniqueísmo que raya lo propagandístico. Como es habitual en muchos de sus textos, sobre un análisis de gran potencia teórica se erige un monumento de voluntarismo e ingenuidad políticos que anega la noción de democracia en una nebulosa cuasi-anarquista hecha 
línea del capítulo XI, el último del libro, dedicado a la democracia, se afirma que el Estado que llamamos democrático es totalmente absoluto.

En el análisis del capítulo X del Tratado político nos hemos ocupado de la inversión genealógica de las formas de Estado ${ }^{77}$. Este principio tendría la cualidad de permitir no sólo una reconstrucción no valorativa o esencialista de la democracia, sino la de establecer los fundamentos sobre los que tal forma de Estado es siquiera posible, así como su carácter constitutivamente conflictivo. Y, además, y en sintonía con su sistema ontológico (no jerárquico), fundamenta el carácter no substancial (por metafísico) de la condición política concreta de las secciones de la sociedad: nadie es patricio o plebeyo más que en relación con los otros componentes de la sociedad y dentro de unas relaciones materiales dadas y de unas condiciones técnicas, nunca fuera o antes de ellas ${ }^{78}$.

Podríamos establecer una sencilla clasificación para resumir las diferencias entre las tres formas de Estado, ahora que ya las tenemos a la vista, siquiera someramente, según criterios cuantitativos y cualitativos, taxonomía aplicada por Aristóteles en la Politica:

Diferencias entre Estado Monárquico y Aristocrático:

- A escala cuantitativa: El Consejo de la Monarquía es mucho más reducido.

- A escala cualitativa: El Consejo de la Aristocracia es considerado eterno pues no depende de la naturaleza coyuntural de un sujeto humano (o depende mucho menos), sino de la estabilidad de la ley a través del carácter permanente del Consejo, cuyos miembros son reemplazados.

\section{Diferencias entre Estado Aristocrático y Democrático:}

- A escala cuantitativa: El Consejo de la Aristocracia es (o suele ser) más reducido.

- A escala cualitativa: El Consejo de la Aristocracia es electivo, el de la Democracia no $^{79}$.

El capítulo XI comienza con la ya mencionada diferencia entre el Estado aristocrático y el democrático, según el criterio cualitativo referente al origen de los designados en el Consejo Supremo ${ }^{80}$. Como es claro, el criterio de diferenciación no es, aquí, el número, pues podría darse el caso de un Consejo aristocrático más numeroso

de consignas, más celebrada que precisada. Por su parte, Balibar (op. cit., pp. 89 y 138) incide en el carácter absoluto del poder y habla de una democratización, basada en la identificación tendencial, de un modo u otro y en distintos grados, de multitud y poder, en toda forma de Estado.

77 Cf. Torres, op. cit., pp. 81-95.

78 "En ciertos lugares, los patricios sólo se eligen de algunas familias. Pero establecerlo así por una ley expresa es pernicioso. Ya que, aparte de que las familias se extinguen con frecuencia y que las excluidas se sienten injuriadas, contradice a la forma de este Estado el que la dignidad patricia sea hereditaria” (TP, VIII, 14, G III, p. 150 [vb]).

79 TP, XI, 2, G III, p. 220 (vb).

${ }_{80}$ "Paso, finalmente, al tercer Estado, el cual es totalmente absoluto y que llamamos democrático. Su principal diferencia del Estado aristocrático consiste, según hemos dicho, en que, en éste, sólo depende de la voluntad y libre elección del Consejo Supremo el que se nombre a este o a aquel patricio. Nadie tiene, pues, derecho hereditario a votar ni a ocupar cargos del Estado ni puede reclamarlo en virtud de algún derecho, como sucede en el Estado de que aquí hablamos. En el Estado democrático, en efecto, todos los que nacieron de padres ciudadanos o en el solio patrio, o los que son beneméritos del Estado o que deben tener derecho de ciudadanía por causas legalmente previstas, todos éstos, repito, con justicia reclaman el derecho a votar en el Consejo Supremo y a ocupar cargos en el Estado, y no se les puede denegar, a no ser por un crimen o infamia” (TP, XI, 1, G III, p. 220 [vb]). 
que uno democrático, sino en el criterio de selección de los que tienen derecho a voto en el Consejo Supremo. El modelo aristocrático parece exigir de los integrantes del Consejo unas determinadas condiciones técnicas ${ }^{81}$. El modelo democrático, sin embargo, unas cualidades étnicas, territoriales o económicas. Según Aristóteles, en Constitución de los atenienses, 26, 3, Pericles propuso la restricción de la ciudadanía a los hijos de padre y madre atenienses, medida que favoreció a las clases popular y media, ya que las viejas aristocracias tenían lazos con familias de las demás polis griegas e, incluso, no griegas. Tampoco es casual que no pueda concebirse la democracia ateniense sin el hecho de que son los ciudadanos libres los que forman parte del ejército, no los esclavos o los metecos. Así como la distinción entre los vocablos

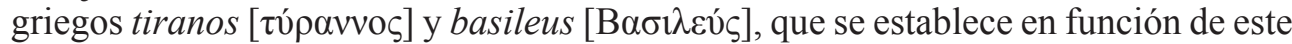
criterio. El primero hace referencia a un rey elegido. El segundo, a uno que detenta el poder por vía hereditaria. De modo, que para la mentalidad convencional de la Antigua Grecia, el tirano era más bien el rey extranjero o el jefe militar que era seleccionado o se imponía por la fuerza, muchas veces apoyado por sectores numerosos de los ciudadanos, por lo que, al cabo, cumplía los rasgos característicos del demagogo. El peso peyorativo del término tirano fue imponiéndose por las políticas concretas y los abusos de poder que en tales situaciones se dieron con frecuencia. El basileus era, por el contrario, el rey legítimo por vía sanguínea o dinástica ${ }^{82}$.

La hipótesis de Spinoza puede resultar chocante. El carácter claramente antiutópico de su pensamiento podría sugerir que un modelo aristocrático sería el más adecuado, si no en abstracto o formalmente, sí en función de las características generales o tendenciales de la naturaleza humana, incapaz de gobernarse a sí misma. Y, sin embargo, es esa naturaleza humana, que es tan constitutiva de la multitud como de los integrantes de un consejo selecto, sujetos igualmente a la inercia marcada por la correspondiente cadena múltiple de determinaciones, la que impide la idoneidad de la aristocracia como forma de Estado. Si los miembros de un consejo aristocrático se guiaran por la razón, esto es, si no fueran humanos, el Estado aristocrático sería el óptimo ${ }^{83}$. Pero como ya expuso Aristóteles en su Política, toda forma de Estado se agita en medio de una gradación cuyos extremos límite son la forma sana de cada modelo (Monarquía, Aristocracia y Politeia) y sus modos patológicos (Tiranía, Oligarquía y Demagogia o Demokratia ${ }^{84}$ ). La fórmula aristotélica es "la ley es razón (nous) sin deseo ${ }^{85}$ ". La fórmula que aquí ofrece Spinoza para designar su reverso es "una voluntad libre de toda ley" ${ }^{\text {" }}$. La aristocracia, por sí misma, no garantiza el gobierno de la ley ni la estabilidad del Estado. De hecho, ninguna forma de Estado los garantiza, pues el sistema spinoziano no admite esencialismo ni fundamentalismo alguno que conciba un régimen político como bueno per se. Su virtud política depende de unas condiciones muy precisas que, a su vez, dependen de circunstancias externas e internas en continua transformación.

81 TP, XI, 2, G III, p. 220 (vb).

82 Cf. P. Fernández Uriel, Historia Antigua Universal, II. El Mundo Griego, Madrid, UNED, 2014, p. 236.

83 "nullum esset imperium cum aristocratico comparandum".

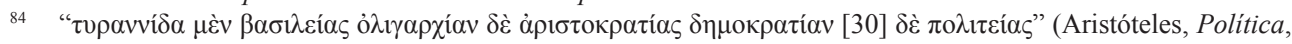
IV, 1289a).

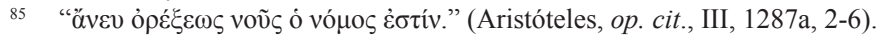

${ }^{86}$ "libera sive omni lege soluta voluntate". Cf. sobre la negación del papel de Dios como legislador TTP, IV, G III, p. 63 (ejemplo de Adán), y XIX, p. 231. A este respecto, se daría en paralelo en el plano de la política: É. Balibar, op. cit., pp. 31, 118 y ss, 135. Cf. TP, IV, 5, G III, p. 58 (vb) y 6, p. 60 (vb), X, 4-6, G III, p. 74 ss (vb). Cf. Epístola L (Balibar, op. cit., p. 121). Cf. intr. a E, p. 37-38, por V. Peña, op. cit. 


\section{Democracia ficción}

La modalidad de democracia de la que parece ocuparse Spinoza es, según la taxonomía aristotélica, la de la sana o estable, no la de la degenerada ${ }^{87}$. Los requisitos que han de satisfacer los que en tal modalidad integran el Consejo Supremo son: ser miembros de la patria ("patriis legibus solis"), ser autónomos ("sui iuris"), es decir, no dependientes económica, física o jurídicamente, y no estar condenados por delitos ("honesteque vivunt"). Para una comparativa con la democracia ateniense, ver, por ejemplo, Aristóteles, Constitución de los atenienses, en la que se hace un recorrido por las fases de la historia política de Atenas teniendo en cuenta, como factor esencial, las condiciones del estatuto de ciudadano y de su participación en la Asamblea y en el Areópago o magistratura, en cada caso ${ }^{88}$. Dado que la democracia es una forma de Estado en la cual los sujetos son operativos políticamente como individuos, puede establecerse una analogía con las aporías del infinito de Zenón (el paso al infinito y el cálculo infinitesimal) que pueden abrir el análisis a los problemas que la noción misma de individuo (átomo) genera. Si seguimos esta propuesta, el individuo queda rebasado por su división hasta el infinito, ya que habría que decidir en función de qué detener la división en algún momento. Dicho de otro modo, cualquier definición de individuo no puede basarse más que en una operación de cirugía conceptual. Sólo podrá determinarse dentro de qué límites y en función de qué parámetros se considera la condición de ciudadano como ficción jurídica, administrativa y política en el marco de las instituciones correspondientes. Nunca fuera de él. Según se ha indicado ya, el individuo (atómico) es un concepto límite. No hay individuo puro, por lo cual no puede haber libertad individual. Todo individuo es un constructo, efecto de la amalgama de afecciones y relaciones que a su vez afecta y se relaciona con otros individuos en procesos dinámicos y conflictivos de causación múltiple. Del mismo modo, la libertad es también un constructo institucional, que no existe fuera o antes de las instituciones, que la hacen posible, pero no a escala individual, pues las instituciones operan necesariamente con grupos atributivos de individuos, cuya identidad se construye pletóricamente, en bloques más o menos maleables. Si se toma como parámetro de la democracia la libertad, ¿puede ser fundamentada la democracia sobre la base de una filosofía materialista como la de Spinoza? Más bien, hay que decir sin escrúpulo que el sistema filosófico de Spinoza devasta las mitologías del idealismo democrático que sueñan una libertad pura, variante laica del libero arbitrio escolástico, como fundamento de una Sagrada Democracia sin aristas ni contaminaciones, trasunto a su vez de la Gracia Divina que bendice los Pueblos. Las paradojas de la democracia, presentes ya en Platón y Aristóteles, condenan a este idealismo a un callejón sin más salida que la doble alternativa reconocida en la República: fanáticos ("los que se pelean por vanas sombras") y corruptos ("los que aman el Poder como si éste fuera un bien") ${ }^{89}$. Spinoza, por tanto, maneja la noción de libertad a diferentes escalas ontológicas, que habrá que precisar según corresponda ${ }^{90} \mathrm{y}$ que disuelven la unidad metafísica de la Libertad guiando al Pueblo, vaporoso cimiento retórico sobre el que se levanta el ejercicio del Poder.

\footnotetext{
"praeterea sui iuris sunt honesteque vivunt".

TP, XI, 3, G III, p. 222 (vb).

Platón, República, Madrid, Gredos, 2006, VII, 520c-d.

É. Balibar, op. cit., p. 119.
} 